\title{
Şizofreni hastalarında antipsikotiklerin depresyon düzeyine etkisi: klozapine karşı diğer atipik antipsikotikler
}

\author{
The effects of antipsychotic drugs on depression level in patients with schizophrenia: clozapine vs. other \\ atypical antipsychotics
}

\author{
Hülya Ertekin ${ }^{1}$, Hatice Yardım Özayhan ${ }^{2}$, Mehmet Er $^{2}$, Burkay Yakar ${ }^{3}$ \\ ${ }^{1}$ Ruh Sağlığı ve Hastalıkları Ana Bilim Dalı, Tıp Fakültesi, Çanakkale Onsekiz Mart Üniversitesi, Çanakkale, Türkiye \\ ${ }^{2}$ Beyhekim Psikiyatri Kliniği, Konya Eğitim ve Araştırma Hastanesi, Konya, Türkiye \\ ${ }^{3}$ Gülabibey Aile Sağllğı Merkezi, Çorum, Türkiye
}

\section{ÖZET}

Giriş: Depresif belirtiler şizofreninin hemen tüm evrelerinde görülmektedir. Şizofreni tedavisinde kullanılan antipsikotik ilaçlar arasında tedaviye dirençli şizofrenide en etkili antipsikotik olan klozapin'in bu hasta grubunda intihar riskini azalttığı bilinmektedir. $\mathrm{Bu}$ çalışmanın amacı klozapin kullanan şizofreni hastalarında depresyon düzeyini saptamak, diğer atipik antipsikotik ilaçları kullanan hastalarla karşılaştırmaktır.

Yöntem: Bu çalışma Aralık 2012-Mayıs 2013 tarihleri arasında DSM-IV-TR’ye göre şizofreni tanılı hastaların değerlendirildiği kesitsel-tanımlayıcı bir çalışmadır. Tüm katılımcıların demografik özellikleri ve Kısa Psikiyatrik Değerlendirme Ölçeği (KPDÖ), Pozitif ve Negatif Sendrom Ölçeği (PNSÖ) ve Calgary Şizofrenide Depresyon Ölçeği (CŞDÖ) puanları değerlendirildi.

Bulgular: Hastaların \%23,6’sı $(\mathrm{n}=13)$ klozapin, \%76,4’ü $(\mathrm{n}=42)$ diğer antipsikotikleri kullandığı tespit edildi. Klozapin kullanan hastaların \%23,1'i $(n=3)$ kadın, \%76,9“u $(n=10)$ erkekti. Klozapin kullanan hastaların yaş ortalaması 43,0 $\pm 11,2$ idi. Klozapin kullanan hastaların depresyon düzeyi $\% 15,4(\mathrm{n}=2)$ olarak bulundu. Klozapin kullanan ve kullanmayan hastaların yaş, cinsiyet, medeni durum, eğitim süreleri, hastalık başlangıç yaşı, depresyon varlı̆̆ı, intihar girişimi öyküsü değerlendirildiğinde her iki grup arasında istatistiksel olarak anlamlı fark saptanmadı.

Sonuç: Şizofreni hastalarında klozapin kullanımının depresyon düzeylerini etkilemediği ve diğer antipsikotikler ile kıyaslandığında depresyon üzerinde farklı bir etkileri olmadığı tespit edilmiştir.

Anahtar kelimeler: atipik antipsikotikler, depresyon, klozapin, şizofreni

\begin{abstract}
Introduction: Depressive symptoms may occur in all stages of schizophrenia disorder. Clozapine is the only antipsychotic that has been demonstrated superior efficacy in schizophrenia and suicidal ideation. The aim of this study is to evaluate depressive symptoms in patients with schizophrenia treated with clozapine and to compare with treated with other atypical antipsychotics.

Methods: A cross-sectional descriptive study was carried out on patients with schizophrenia according to DSM-IV-TR between December 2012 and May 2013. All participants were evaluated for demographic characteristics and points of Brief Psychiatric Rating Scale, Positive, Negative Syndrome Scale, and Calgary Depression Scale for Schizophrenia.

Results: A total $23.6 \%(\mathrm{n}=13)$ patients treated with clozapine, while $76.4 \%(\mathrm{n}=42)$ patients were treated with other antipsychotic drugs. $23.1 \%(n=3)$ of patients taking clozapine were women, $76.9 \%(n=10)$ were male. The mean age of patients treated with clozapine was $43.0 \pm 11.2$. The level of depression of patients treated with clozapine was $15.4 \%(\mathrm{n}=2)$. No statistically significant difference was found between patients between treated with clozapine and other antipsychotics regarding age, sex, marital status, education years, work history, age at onset of disease, depression and history of suicide attempt

Conclusion: As a result of this study it is found that clozapine did not effect on the level of depression in patients with schizophrenia, and depression level of patients with schizophrenia treated with clozapine had no difference from patients treated with other antipsychotics.
\end{abstract}

Keywords: atypical antipsychotics, clozapine, depression, schizophrenia

Başvuru / Submission: Mart / March 11, 2016

Kabul / Acceptance: Haziran / June 2, 2016

Yazışma / Correspondence: Dr. Hülya Ertekin, Ruh Sağlığı ve Hastalıkları Ana Bilim Dalı, Tıp Fakültesi, Çanakkale Onsekiz Mart Üniversitesi, Çanakkale, Türkiye

E-mail: md.ertekin@gmail.com

Atıf / Cite: Ertekin H, Özayhan HY, Er M, Yakar B. Şizofreni hastalarında antipsikotiklerin depresyon düzeyine etkisi: klozapine karşı diğer atipik antipsikotikler. Fam Pract Palliat Care. 2016;1(2):31-34 


\section{GíRiș}

Şizofreni hastalık süresi boyunca hastaların \%60 kadarında görülen depresif bulgular, hastalığın hemen hemen tüm evrelerinde görülmektedir [1]. Depresyon varlığı bu hastaların yaşam kalitesini düşürmekte, hastaneye yatış sayılarını, intihar riskini, komorbid diğer psikiyatrik hastalıkların görülme sıklı̆̆ını arttırmaktır [2, 3] Yapılan çalışmalar bu hastalarda \%25-81 oranında depresyon eș tanısı saptamıştır [4].

Şizofreni tedavisinde kullanılan antipsikotik ilaçlar arasında tedaviye dirençli şizofrenide en etkili antipsikotik olan klozapinin bu hasta grubunda intihar riskini azalttığ bilinmektedir [5]. Klozapinin şizofreni hastalarında depresif belirtileri düzeltip düzeltmediğini araştıran çok sayıda çalışma ve kanıt bulunmamaktadır. Yapılan bazı çalışmalar klozapinin depresif belirtileri azaltmada diğer antipsikotik ilaçlardan daha etkili olduğunu gösterirken [6, 7] bazı çalışmalar aralarında anlamlı fark olmadığını $[8,9]$ bildirmektedir.

$\mathrm{Bu}$ bağlamda bu çalışmanın amacı klozapin kullanan şizofreni hastalarında depresyon düzeyini saptamak, diğer antipsikotik ilaçları kullanan hastalarla karşılaştırmaktır.

\section{YÖNTEM}

Bu çalışma Konya Eğitim ve Araştırma Hastanesi, Beyhekim Psikiyatri Kliniği, Psikotik Bozukluklar Polikliniğine Aralık 2012-Mayıs 2013 tarihleri arasında başvuran hastaların tıbbi kayıtlarının geriye dönük incelenmesi sonucu yapılmış kesitsel-tanımlayıcı bir çalışmadır.

DSM-IV-TR'ye göre şizofreni tanısı olan ve depresyon tedavisi amacıyla antidepresan ilaç tedavisi almayan hastalar çalışmaya dahil edildi. Çalıșmaya dahil edilme kriterleri; 18 yaş ve üzeri olma, testleri anlamayı ve görüşmeyi sürdürmeyi engelleyecek derecede zihinsel geriliği olmama, bilinen organik beyin hastalığı öyküsü olmama olarak belirlendi.

Tüm katılımcıların demografik ve klinik özelliklerini belirlemeye yönelik demografik veri formu ile genel psikopatolojiyi saptamak amaciyla Kısa Psikiyatrik Değerlendirme Ölçeği (KPDÖ), Pozitif ve Negatif Sendrom Ölçeği (PNSÖ) puanları değerlendirildi. Depresif belirtiler Calgary Şizofrenide Depresyon Ölçeği (CŞDÖ) ile yapıldı. ÇŞDÖ ölçeği-Türkçe versiyonunun depresif bozukluğun eşlik ettiği şizofreni için kesme puanı 11/12 olarak belirlenmiştir [10]. Antipsikotik ilaçların yan etkilerini değerlendirmek amaciyla Simpson Angus Nöroleptiklere Bağlı Hareket Bozukluklarını Değerlendirme Ölçeği (SAÖ) ve Barnes Akatizi Ölçeği (BAÖ) kullanıldı.

\section{İstatistiksel Analiz}

Elde edilen veriler SPSS 19.0 for Windows (SPSS, Inc., Chicago, IL) programı ile analiz edildi. Demografik verilerin kategorik olanların karşılaştırılmasında ki kare testi, kategorik olmayan verilerin karşılaştırılmasında student $t$ testi kullanıldı. p değerinin 0.05 'ten küçük olduğu değerler istatistiksel olarak anlamlı kabul edildi.

\section{BULGULAR}

Klozapin kullanan 13 hasta, kullanmayan 42 hasta çalışmaya alındı. Klozapin kullanan hastaların \%23,1'i kadın, $\% 76,9^{\circ} \mathrm{u}$ erkekti. Klozapin kullanan hastaların yaş ortalaması $43,0 \pm 11,2$, diğer antipsikotikleri kullanan hastaların yaş ortalaması 41,6 $\pm 10,6$ saptandi. Klozapin kullanan ve kullanmayan hastaların demografik verilerinin karşılaştırmasında iki grup arasında istatistiksel fark saptanmadi (Tablo 1).

Tablo 1. Demografik veriler ve depresyon; klozapine karşı diğer antipsikotikler, $n$ \%

$$
\begin{array}{ll}
\text { Klozapin } & \begin{array}{l}
\text { Diğer } \\
\text { antipsikotikler }
\end{array} \\
(\mathrm{n}=13, \% 23,6) & (\mathrm{n}=42, \% 76,4)
\end{array}
$$

Cinsiyet

$\begin{array}{clll}\text { Kadın } & 3(23,1) & 18(42,9) & 0,32 \\ \text { Erkek } & 10(76,9) & 24(57,1) & \\ \text { Yaş* } & 43,0 \pm 11,2 & 40,9 \pm 10,2 & 0,52 \\ \text { Hastalık } & 21,5 \pm 5,6 & 25,3 \pm 9,6 & 0,17\end{array}$

başlangıç

yaşı*

Medeni

durum

$\begin{array}{clll}\text { Bekâr } & 5(38,5) & 18(42,9) & 0,68 \\ \text { Evli } & 5(38,5) & 11(26,2) & \\ \text { Boşanmış } & 3(23,1) & 13(31,0) & \\ \text { Dul } & 0 & 0 & \end{array}$

$\begin{array}{llll}\text { Eğitim } & 6,8 \pm 3,0 & 6,7 \pm 2,7 & 0,65\end{array}$

süresi*

İntihar

girişimi

Var $1(7,7) \quad 12(28,6) \quad 0,16$

Yok $12(92,3) \quad 30(71,4)$

Hastaneye $\quad 6,5 \pm 4,7 \quad 5,4 \pm 5,7 \quad 0,52$

yatış

say1s1*

Depresyon

$\begin{array}{lll}\text { Var } & 2(15,4) & 6(14,3) \\ \text { Yok } & 11(84,6) & 36(85,7)\end{array}$

*;Ortalama \pm standart sapma 
KPDÖ ve PNSÖ pozitif, negatif, genel ve toplam puanları, CŞDÖ, BAÖ ve SAÖ arasında her iki grup arasında anlamlı istatistiksel fark saptanmadi (Tablo 2).

Tablo 2. Ölçek puanlarının karşılaştırılması, ortalama \pm standart sapma (ss)

\begin{tabular}{llll}
\hline & Klozapin & $\begin{array}{l}\text { Diğer } \\
\text { Antipsikotikler }\end{array}$ & $\mathbf{p}$ \\
\hline PNSÖ & & & \\
Pozitif & $12,5 \pm 4,6$ & $10,5 \pm 2,5$ & 0,14 \\
Negatif & $17,0 \pm 5,3$ & $14,8 \pm 6,1$ & 0,24 \\
Genel & $25,8 \pm 5,3$ & $22,4 \pm 6,9$ & 0,11 \\
Toplam & $53,8 \pm 10,1$ & $48,6 \pm 13,4$ & 0,20 \\
KPDÖ & $18,2 \pm 8,2$ & $16,7 \pm 7,8$ & 0,53 \\
ÇŞDÖ & $5,9 \pm 3,6$ & $5,6 \pm 3,7$ & 0,57 \\
BAÖ & $0,2 \pm 0,4$ & $0,2 \pm 0,4$ & 0,53 \\
SAÖ & $1,3 \pm 0,8$ & $1,0 \pm 1,1$ & 0,42 \\
\hline PNSÖ; Pozitif & &
\end{tabular}

PNSÖ; Pozitif ve Negatif Sendrom Ölçeği

KPDÖ; Kısa Psikiyatrik Değerlendirme Ölçeği

CÇDÖ; Calgary Şizofreni Depresyon Ölçeği

BAÖ; Barnes Akatizi Ölçeği

SAÖ; Simpson Angus Nöroleptiklere Bağlı Hareket

Bozukluklarını Değerlendirme Ölçeği

Klozapin kullanan hastaların ortalama ilaç dozu 364,3 \pm 151,2 mg/gün idi. Bu hastaların altısı başka bir antipsikotikle klozapini kombine kullanıyordu. Her hastada ek olarak sadece biri kullanılmak üzere bu ilaçlar; olanzapin, risperidon, aripiprazol, amisülpirid, paliperidon ve ketiapin şeklindeydi.

Klozapin $(n=13)$ ve risperidon kullanan hastalar $(n=8)$ arasında depresyon tanı oranları açısından fark saptanmadı $(\% 15,4$ ve $\% 12,5$, sirasiyla, $p=0,525)$. Klozapin ve risperidon kullanan hastalar CŞDÖ puanlarına göre kıyaslandığında anlamlı fark görülmedi $(5,9 \pm 3,6$ ve $6,3 \pm 3,6$, sirasıly, $\mathrm{p}=$ 0,200).

Klozapin $(n=13)$ ve olanzapin kullanan hastalar $(n=16)$ karşılaştırıldığında arasında depresyon tanı oranları açısından fark saptanmadı $(\% 15,4 ; n=2$ ve $\% 25,0 ; n=4$, sirasıly, $\mathrm{p}=$ 0,854). CŞDÖ ortalama puanları karşılaştırıldığında olanzapin ve klozapin kullanan hastalar arasında istatistiksel fark yoktu $(7,5 \pm 3,8$ ve $5,9 \pm 3,6$, sirasiyla, $p=0,265)$.

\section{TARTIŞMA}

Özellikle şizofreni gibi tüm evrelerinde depresif belirtilerin eşlik ettiği bir hastalıkta, depresif belirtiler için kullanılan tedavi rejimlerini ön plana çıkarmaktadır. Bu çalışma klozapin kullanan hastalar ile diğer antipsikotikleri kullanan hastaları, CŞDÖ ile depresif belirti sıklığını değerlendiren ülkemizde yapılmış ilk çalışmalardan biri olması açısından önemlidir.

Çalışmamızda klozapin kullanan ve kullanmayan hastaların CŞDÖ'ye göre depresyon düzeylerinde ilgili çalışmaların aksine anlamlı fark saptanmadı. Yapılan önceki çalışmalarda klozapin kullanan hastaların depresyon düzeylerinin azaldığı bildirilmişken [6, 7], Lindenmayer ve ark'larının yaptığı bir çalışmada klozapin, risperidon ve olanzapin kullanan hastaların depresyon düzeyleri arasında fark saptanmamıştır [8]. Yapılan bu çalışmalarda kullanılan ölçekler açısından fark görülmektedir. $\mathrm{Bu}$ çalışmalardan birinde Hamilton depresyon ölçeği, diğerinde PNSÖ ve ötekisinde CŞDÖ kullanılmıştır [6-8]. Bu çalışmaların çalışmamızdan diğer bir farkı ise takip çalışması olmalarına karşı bizim çalışmamızda daha önceden bilinen depresyonu olmayan hastaların anlık değerlendirilmesi sonucu veriler elde edilmesidir.

Çalışmamızın sonuçlarından biri de; risperidon veya olanzapin kullanan hastalarla, klozapin kullanan hastaların depresyon puanları ve depresyon durumları arasında anlamlı istatistiksel fark saptanmamış olmakla birlikte risperidon ve olanzapin kullanan hastaların CŞDÖ ortalama puanları klozapin kullananlardan yüksekti. Çalışmamızın sonuçlarıyla benzerlik gösteren bir çalışmada klozapin, risperidon ve olanzapin kullananlar arasında fark saptanmamıştır [9]. Nakajima ve ark'larının yaptığı bir diğer çalışmada da olanzapin kullanan hastalarla klozapin kullanan hastalar arasında fark saptanmamıştır [11]. Yapılan çalışmalarda ve bizim çalışmamızda az sayıda hastanın değerlendirilmiş olması verilerin istatistiksel olarak anlamlı düzeylere ulaşmasına engel olmuş olabilir.

Çalışmamız Klozapin kullanımı ile demografik bulgular, bazı klinik özellikler ve depresif belirtilerin ilişkisini incelemesi bakımından oldukça önemlidir. Ancak bu çalışmanın bazı kısıtlılıkları mevcuttur. Çalışmamız kısıtlılıkları arasında; az sayıda hastanın verilerinin incelenmesi sonucu elde edilmiş olması, hastaların uzunlamasına takipteki durumlarının incelenmemiş olması, klozapin kullanan hasta sayısının yetersiz olması sayılabilir.

Sonuç olarak çalışmamızda şizofreni hastalarında klozapin kullanımının depresyon düzeylerini etkilemediği ve diğer antipsikotikler ile kıyaslandığında depresyon üzerinde farklı bir etkileri olmadığ 1 tespit edilmiştir. Bu konuda gelecekte yapılacak çok sayıda hastanın değerlendirildiği, yüksek sayıda klozapin kullanan hastanın değerlendirildiği takip çalışmalarına ihtiyaç vardır.

Çıkar çatışması: Bildirilmedi.

Finansal destek: Bildirilmedi.

\section{KAYNAKLAR}

1. Siris S. Diagnosis of secondary depression in schizophrenia: implications for DSM-IV. Schizophr Bull 1991;17:75-98.

2. Zisook S, McAdams LA, Kuck J, et al. Depressive symptoms in schizophrenia. Am J Psychiatry 1999; 56:1736-1743.

3. Schennach-Wolff R, Obermeier M, Seemüller F, et al. Evaluating depressive symptoms and their impact on outcome in schizophrenia applying the Calgary Depression Scale. Acta Psychiatr Scand 2011;123:228238.

4. Siris SG. Suicide and schizophrenia. J Psychopharmacol. 2001;15(2):127-135.

5. Leucht S, Cipriani A, Spineli L, et al. Comparative efficacy and tolerability of 15 antipsychotic drugs in 
schizophrenia: a multiple-treatments meta-analysis. Lancet. 2013;382(9896):951-962.

6. Breier AF, Malhotra AK, Su TP, et al. Clozapine and Risperidone in chronic schizophrenia: effects on symptoms, parkinsonian side effects, and neuroendocrine response. Am J Psychiatry. 1999;156(2):294-298.

7. Azorin JM, Spiegel R, Remington G, et al. A doubleblind comparative study of clozapine and Risperidone in the management of severe chronic schizophrenia. Am J Psychiatry. 2001;158(8):1305-1313.

8. Lindenmayer JP, Czobor P, Volavka J, et al. Effects of atypical antipsychotics on the syndromal profile in treatment resistant schizophrenia. J Clin Psychiatry. 2004;65(4):551-556.

9. Lewis SW, Barnes TR, Davies L, et al. Randomized controlled trial of effect of prescription of clozapine versus other second generation antipsychotic drugs in resistant schizophrenia. Schizophr Bull. 2006;32(4):715723.

10. Aydemir Ö, Esen Danacı A, Deveci A, İçelli İ. Calgary şizofrenide depresyon ölçeği'nin Türkçe versiyonunun güvenilirliği ve geçerliliği. Nöropsikiyatri Arşivi 2000;37:82-86.

11. Nakajima S, Takeuchi H, Fervaha G, et al. Comparative efficacy between clozapine and other atypical antipsychotics on depressive symptoms in patients with schizophrenia: analysis of the CATIE phase 2E data. Schizophr Res. 2015 Feb;161(2-3):429-33. 